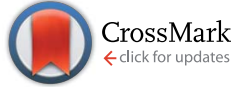

Cite this: Chem. Sci., 2017, 8, 1097

Received 4th August 2016

Accepted 15th September 2016

DOI: $10.1039 / c 6 s c 03468 c$

www.rsc.org/chemicalscience

\section{Geminal bis-borane formation by borane Lewis acid induced cyclopropyl rearrangement and its frustrated Lewis pair reaction with carbon dioxide $\uparrow$}

\author{
Yun-Lin Liu, Gerald Kehr, Constantin G. Daniliuc and Gerhard Erker* \\ Cyclopropylacetylene reacts with two molar equivalents of Piers' borane $\left[\mathrm{HB}\left(\mathrm{C}_{6} \mathrm{~F}_{5}\right)_{2}\right]$ under mild conditions \\ by an addition/rearrangement sequence with cyclopropyl ring opening to give a mixture of two $\alpha-B\left(C_{6} F_{5}\right)_{2}$ \\ substituted tetrahydroboroles. This compound forms an active frustrated Lewis pair with $\mathrm{P}^{t} \mathrm{Bu}_{3}$ that \\ heterolytically splits dihydrogen and adds carbon dioxide as a geminal chelate bis-boryl component. The \\ respective reactions of the two-fold $\mathrm{HB}\left(\mathrm{C}_{6} \mathrm{~F}_{5}\right)_{2}$ addition to $\mathrm{Ph}-\mathrm{CH}_{2} \mathrm{CH}_{2} \mathrm{C} \equiv \mathrm{CH}$ were studied as a geminal \\ Lewis acid reference. Most of the products were characterized by $\mathrm{X}$-ray diffraction.
}

\section{Introduction}

Bis-boranes featuring pairs of strongly Lewis acidic $\mathrm{B}\left(\mathrm{C}_{6} \mathrm{~F}_{5}\right)_{2}$ groups should be ideally matching templates for binding of $\mathrm{CO}_{2}$ under frustrated Lewis pair (FLP) conditions. Although such geminal bis-boranes are principally readily available from terminal alkynes by sequential hydroboration reactions with two molar equivalents of $\mathrm{HB}\left(\mathrm{C}_{6} \mathrm{~F}_{5}\right)_{2}$, as it has been shown by Piers et al., ${ }^{\mathbf{1 , 2}}$ surprisingly little is known about this $\mathrm{CO}_{2}$-trapping reaction. Stephan et al. had used Siebert's unsaturated geminal $\mathrm{BCl}_{2}$ compound 1 (ref. 3) and the corresponding $\mathrm{B}\left(\mathrm{C}_{6} \mathrm{~F}_{5}\right)_{2}$ analogue 2 , which was derived from $\mathbf{1}$ by treatment with $\mathrm{Zn}\left(\mathrm{C}_{6} \mathrm{~F}_{5}\right)_{2}$, for $\mathrm{FLP} / \mathrm{CO}_{2}$ scavenging, ${ }^{4}$ but the vast majority of $\mathrm{FLP} / \mathrm{CO}_{2}$ chemistry used non-chelate Lewis acidic binding motifs $^{5,6}$ (Scheme 1).

We have now investigated the ${ }^{t} \mathrm{Bu}_{3} \mathrm{P} / \mathrm{CO}_{2}$ trapping reaction using a pair of geminal $\mathrm{C}_{6} \mathrm{~F}_{5}$ containing bis-boranes. Both were obtained by the treatment of the respective terminal acetylene starting materials with two molar equivalents of Piers' borane $\left[\mathrm{HB}\left(\mathrm{C}_{6} \mathrm{~F}_{5}\right)_{2}\right]$. While we observed the expected normal behaviour upon reacting the alkyne $\mathrm{Ph}-\mathrm{CH}_{2} \mathrm{CH}_{2} \mathrm{C} \equiv \mathrm{CH}$ (5a) with the hydroboration reagent, we observed a rather complex rearrangement behaviour that took place upon the treatment of cyclopropylacetylene $(\mathbf{5 b})$ with the $\mathrm{HB}\left(\mathrm{C}_{6} \mathrm{~F}_{5}\right)_{2}$ borane. The characterization of the resulting special rearrangement product, its formation and its FLP reaction with $\mathrm{CO}_{2}$ in the presence of a tert-phosphine will be presented and discussed in this account.

Organisch-Chemisches Institut, Universität Münster, Corrensstraße 40, 48149 Münster, Germany.E-mail: erker@uni-muenster.de

$\uparrow$ Electronic supplementary information (ESI) available: Experimental and analytical details are given. CCDC 1487577-1487584. For ESI and crystallographic data in CIF or other electronic formats see DOI: $10.1039 / \mathrm{c} 6 \mathrm{sc} 03468 \mathrm{c}$

\section{Results and discussion}

\section{The $\mathrm{Ph}-\mathrm{CH}_{2} \mathrm{CH}_{2} \mathrm{C} \equiv \mathrm{CH} / 2 \mathrm{HB}\left(\mathrm{C}_{6} \mathrm{~F}_{5}\right)_{2}$ system}

Terminal acetylenes undergo regioselective 1,2-hydroboration with the $\mathrm{HB}\left(\mathrm{C}_{6} \mathrm{~F}_{5}\right)_{2}$ reagent to yield the respective substituted vinyl boranes. ${ }^{7}$ When the reaction is carried out in a $1: 2$ molar ratio of alkyne and $[\mathrm{B}] \mathrm{H}$ borane, the respective saturated geminal bis-borane is obtained in many cases under kinetic control. ${ }^{\mathbf{1}}$ This typical reaction path was also observed when we treated the alkyne 5a with $\operatorname{HB}\left(\mathrm{C}_{6} \mathrm{~F}_{5}\right)_{2}$ in a $1: 2$ ratio in toluene solution at r.t. ( 1 hour reaction time). Workup gave the product 6a, which we isolated as a white solid with a 76\% yield. The compound was characterized by $\mathrm{C}, \mathrm{H}$-elemental analysis and by spectroscopy, and we carried out some characteristic reactions.

Compound 6a shows a single ${ }^{11} \mathrm{~B}$ NMR resonance at $\delta=72.1 \mathrm{ppm}$, which is typical for Lewis acidic planar tricoordinate $\mathrm{R}-\mathrm{B}\left(\mathrm{C}_{6} \mathrm{~F}_{5}\right)_{2}$ situations. ${ }^{8}$ Consequently, we observed the three ${ }^{19} \mathrm{~F}$ NMR signals of the symmetry-equivalent $\mathrm{C}_{6} \mathrm{~F}_{5}$ groups at boron. They show a typical large meta/para fluorine NMR chemical shift difference $\left(\Delta \delta^{19} \mathrm{~F}_{m, p}=13.7 \mathrm{ppm}\right)$. The mixture of compound 6 a with the bulky phosphine $\mathrm{P}^{t} \mathrm{Bu}_{3}(1: 1)$
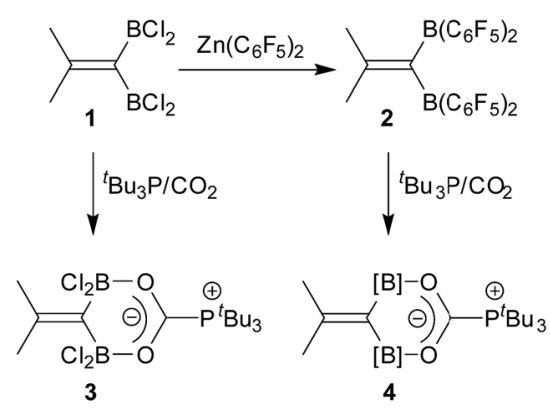

$[\mathrm{B}]: \mathrm{B}\left(\mathrm{C}_{6} \mathrm{~F}_{5}\right)_{2}$

Scheme 1 Geminal bis-boranes and their FLP reactions with $\mathrm{CO}_{2}$. 
represents a reactive frustrated Lewis pair that is able to heterolytically split dihydrogen ${ }^{9}$ under mild conditions (r.t., 2.0 bar of $\mathrm{H}_{2}$, overnight in pentane). The product precipitated from the reaction mixture and was isolated as a white solid with an $87 \%$ yield. Compound 7 was characterized by X-ray diffraction (single crystals were obtained from pentane/dichloromethane at $-35{ }^{\circ} \mathrm{C}$ by the diffusion method).

Compound 7 shows a fully extended all anti-periplanar $\mathrm{C}_{4}{ }^{-}$ chain featuring the phenyl substituent at one end and the geminal pair of boryl groups at the other. The C1-B1/B2 bonds are almost of the same length and the pair of boron atoms is bridged by the hydride (see Fig. 1). In the crystal there is an independent $\mathrm{HP}^{t} \mathrm{Bu}_{3}{ }^{+}$countercation. In solution, compound 7 shows the ${ }^{31} \mathrm{P}$ NMR signal of the $[\mathrm{P}] \mathrm{H}$ phosphonium cation $(\delta=$ $\left.60.2 \mathrm{ppm},{ }^{1} J_{\mathrm{PH}} \sim 430 \mathrm{~Hz}\right)$. The anion shows the single broad ${ }^{11} \mathrm{~B}$ NMR resonance of the symmetry-equivalent pair of $\mathrm{B}\left(\mathrm{C}_{6} \mathrm{~F}_{5}\right)_{2}$ groups in the typical tetracoordinated borate range $(\delta=-18.8 \mathrm{ppm})$. The $\mathrm{C}_{6} \mathrm{~F}_{5}$ groups of the boryl groups are diastereotopic. Therefore, we have observed two sets of $o, p, m-\mathrm{C}_{6} \mathrm{~F}_{5}$ ${ }^{19} \mathrm{~F}$ NMR resonances for these units. The bridging $[\mathrm{B}]-\mathrm{H}-[\mathrm{B}]$ hydride gives rise to a broad ${ }^{1} \mathrm{H}$ NMR signal at $\delta=2.64 \mathrm{ppm}$ (Scheme 2).

We then treated the bis(boryl)alkane/phosphine FLP [6a/ $\left.\mathrm{P}^{t} \mathrm{Bu}_{3}\right]$ with carbon dioxide. Exposure of the $6 \mathrm{a} / \mathrm{P}^{t} \mathrm{Bu}_{3}$ mixture in pentane at r.t. to $\mathrm{CO}_{2}$ (2.0 bar) quickly (in 2 hours) resulted in the formation of a white precipitate of compound $\mathbf{8}$, which was isolated with an $81 \%$ yield. Compound 8 is sensitive in solution $\left(\mathrm{CD}_{2} \mathrm{Cl}_{2}\right)$ and decomposed above $0{ }^{\circ} \mathrm{C}$. Single crystals of the FLP/ $\mathrm{CO}_{2}$ adduct 8 suitable for characterization by X-ray diffraction were obtained from pentane/dichloromethane at $-35{ }^{\circ} \mathrm{C}$ by the diffusion method (see Fig. 2). In the crystal, compound 8 shows a gauche/anti-periplanar conformation of the $\mathrm{Ph}-\mathrm{CH}_{2} \mathrm{CH}_{2} \mathrm{CH}_{2}-$ $\mathrm{CH}$-chain. The geminal pair of $\mathrm{B}\left(\mathrm{C}_{6} \mathrm{~F}_{5}\right)_{2}$ substituents at carbon atom $\mathrm{C} 1$ has taken up the $\mathrm{CO}_{2}$ molecule in a rather symmetric way by forming two boron-oxygen bonds of almost the same

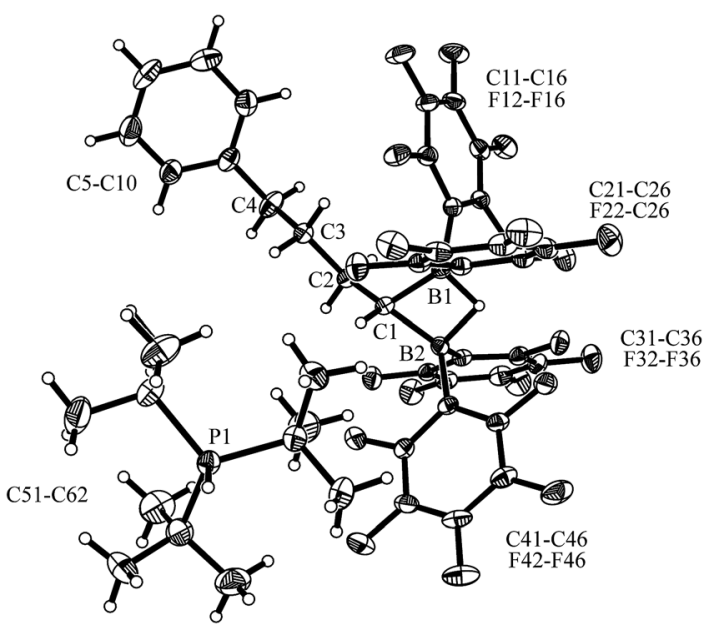

Fig. 1 A projection of the molecular structure of the FLP dihydrogen splitting product 7 (thermal ellipsoids are shown with a 30\% probability level). Selected bond lengths ( $\AA$ ) and angles (degrees): B1‥B2 1.945(5), C1-C2 1.526(4), C1-B1 1.609(5), C1-B2 1.598(5), B1-H01 1.26(4), B2H01 1.34(3), B2-C1-B1 74.7(2), B2-H01-B1 96.9.

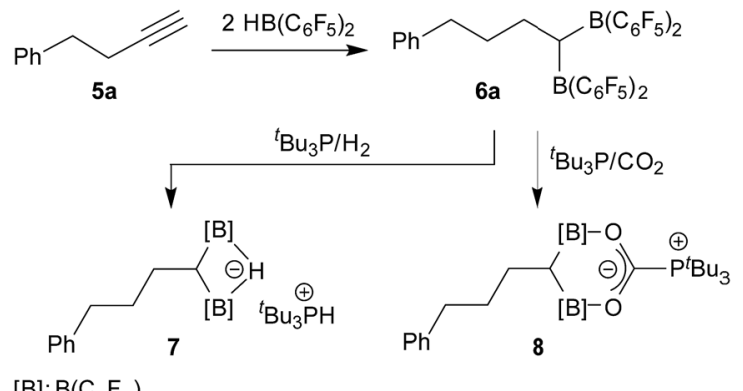

$[\mathrm{B}]: \mathrm{B}\left(\mathrm{C}_{6} \mathrm{~F}_{5}\right)_{2}$

Scheme 2 Frustrated Lewis pair reactions with the geminal bisborane. $6 a$.

length, and also the $\mathrm{C} 5-\mathrm{O} 1 / \mathrm{O} 2$ bonds are almost equal in length, indicating a fully delocalized structure for this submoiety of compound $\mathbf{8}$. The resulting six-membered heterocycle features an almost coplanar arrangement of the BOCOB unit with only the carbon atom $\mathrm{C} 1$ being localized markedly outside of this plane. The bulky $\mathrm{P}^{t} \mathrm{Bu}_{3}$ group is found attached at the central carbon atom $\mathrm{C} 5$ of this heterocyclic subunit of the overall molecular zwitterionic $\mathrm{FLP} / \mathrm{CO}_{2}$ addition product 8 .

In solution we observe the ${ }^{13} \mathrm{C} \mathrm{NMR}$ resonance of the scavenged $\mathrm{CO}_{2}$ molecule at $\delta=172.7 \mathrm{ppm}$ with a ${ }^{1} J_{\mathrm{PC}}$ coupling constant of $92.6 \mathrm{~Hz}$. Compound 8 shows a typical phosphonium ${ }^{31} \mathrm{P}$ NMR signal at $\delta=60.3 \mathrm{ppm}$, and a single broad ${ }^{10} \mathrm{~B}$ NMR resonance at $\delta=10.8 \mathrm{ppm}$. The $\mathrm{C}_{6} \mathrm{~F}_{5}$ groups at the pair of boron atoms are pairwise diastereotopic, giving rise to two equal intensity pairs of $o, p, m{ }^{19} \mathrm{~F}$ NMR features, with a rather small chemical shift difference $\Delta \delta^{19} \mathrm{~F}_{m, p}$ around $5.5 \mathrm{ppm}$, as is typical for borate type structures based on the $\mathrm{B}\left(\mathrm{C}_{6} \mathrm{~F}_{5}\right)_{2}$ subunit.

\section{The cyclopropylacetylene $/ 2 \mathrm{HB}\left(\mathrm{C}_{6} \mathrm{~F}_{5}\right)_{2}$ system: rearrangement to tetrahydroborole derivatives}

We next reacted cyclopropylacetylene (5b) with two molar equivalents of Piers' borane $\left[\mathrm{HB}\left(\mathrm{C}_{6} \mathrm{~F}_{5}\right)_{2}\right]$ (toluene, r.t., 1 hour). In

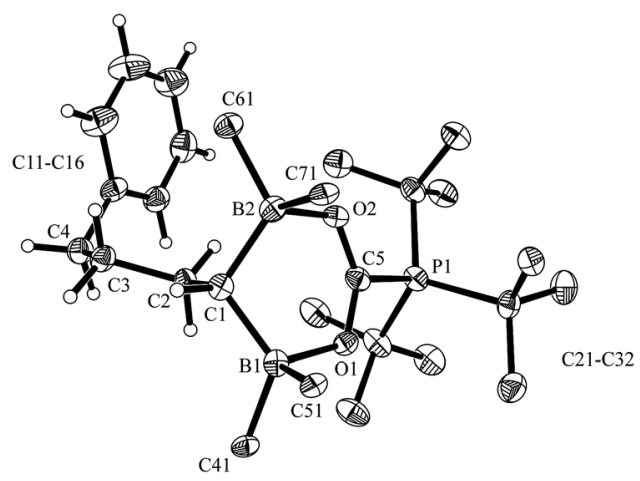

Fig. 2 A view of the molecular structure of the zwitterionic $\mathrm{FLP} / \mathrm{CO}_{2}$ adduct 8 (thermal ellipsoids are shown with a 50\% probability level; hydrogen atoms of the $\mathrm{P}^{t} \mathrm{Bu} 3$ group and the $\mathrm{C}_{6} \mathrm{~F}_{5}$ substituents at boron atoms B1 and B2 are omitted for clarity: for details see the ESI Selected bond lengths ( $\AA$ ) and angles (degrees): B1-O1 1.628(4), B2O2 1.635(4), O1-C5 1.265(4), O2-C5 1.264(4), B2-C1-B1 108.6(2), $\mathrm{O} 2-\mathrm{C} 5-\mathrm{O} 1$ 127.7(3). 
this case, we did not obtain the simple cyclopropyl- $\mathrm{CH}_{2} \mathrm{CH}$ $\left[\mathrm{B}\left(\mathrm{C}_{6} \mathrm{~F}_{5}\right)_{2}\right]_{2}$ product $(6 \mathbf{b})$, but found that a rearrangement had occurred. In situ NMR spectroscopy revealed the formation of a ca. $7: 1$ mixture of the $\alpha$-boryl-tetrahydroborole products cis-9 and trans-9. We isolated the compound cis-9 in an almost pure condition $(96: 4)$ after workup as a pale yellow solid with a $67 \%$ yield (see Scheme 3).

Compound cis-9 was characterized by X-ray diffraction using single crystals that were grown from a pentane solution of the compound at $-35{ }^{\circ} \mathrm{C}$ (see Fig. 3, left). The X-ray crystal structure analysis has shown that a five-membered saturated tetrahydroborole framework had been formed in the reaction, bearing a B $\left(\mathrm{C}_{6} \mathrm{~F}_{5}\right)_{2}$ substituent at the $\alpha$-position $\mathrm{C} 1$, a methyl substituent at $\mathrm{C} 3$ and a $\mathrm{C}_{6} \mathrm{~F}_{5}$ substituent at $\mathrm{C} 4$. The pair of substituents in cis-9 at carbon atoms $\mathrm{C} 1$ and $\mathrm{C} 4$ are cis-oriented; both are in a trans-arrangement with the methyl substituent at carbon atom C3. The plane of the $\mathrm{C}_{6} \mathrm{~F}_{5}$ group at $\mathrm{C} 4$ is oriented markedly away from the mean heterocyclic core [dihedral angle $\theta$ B1-C4-C21$\left.\mathrm{C} 22-119.6(1)^{\circ}\right]$, whereas the $\mathrm{C}_{6} \mathrm{~F}_{5}$ group at the adjacent boron atom $\mathrm{B} 1$ is rotated slightly in the opposite direction $[\theta$ C1-B1C11-C12 49.0(7) $\left.{ }^{\circ}, \mathrm{C} 4-\mathrm{B} 1-\mathrm{C} 11-\mathrm{C} 12-136.2(5)^{\circ}\right]$. Both of the boron atoms B1 and B2 show trigonal planar coordination geometries $\left(\sum \mathrm{B} 1^{\mathrm{ccc}} 359.8^{\circ}, \sum \mathrm{B} 2^{\mathrm{ccc}} 359.9^{\circ}\right)$, which should render these both as strongly Lewis acidic centres. Consequently, we have monitored a pair of ${ }^{11} \mathrm{~B}$ NMR features for compound cis-9 in solution ( $\mathrm{d}_{6}$-benzene) in the typical range of Lewis acidic $\mathrm{B}\left(\mathrm{C}_{6} \mathrm{~F}_{5}\right) \mathrm{R}$ signals $(\delta=78.0 \mathrm{ppm}, 67.6 \mathrm{ppm})$ and a similar appearance of the ${ }^{19} \mathrm{~F}$ NMR spectrum was observed for the $\mathrm{B}\left(\mathrm{C}_{6} \mathrm{~F}_{5}\right)_{2} / \mathrm{B}\left(\mathrm{C}_{6} \mathrm{~F}_{5}\right)$ units $\left[\Delta \delta^{19} \mathrm{~F}_{m, p}=13.9 \mathrm{ppm}, 16.0 \mathrm{ppm}\right]$ (for details, see the ESI†).

We tried to find a mechanistic rationale for the formation of the boryl tetrahydroborole product 9 in the reaction of cyclopropylacetylene (5b) with two $\mathrm{HB}\left(\mathrm{C}_{6} \mathrm{~F}_{5}\right)_{2}$ equivalents. It is known that cyclopropanes are often readily opened to the respective olefin isomers upon exposure to boron Lewis acids. ${ }^{10}$ Therefore, we briefly checked whether the opened isomer of $\mathbf{5 b}, 2$-methyl1-buten-3-yne, might be involved in this reaction. However, this was not the case. Its reaction with two equivalents of $\mathrm{HB}\left(\mathrm{C}_{6} \mathrm{~F}_{5}\right)_{2}$ took a different course (for details, see the ESI $\dagger$ ).

Therefore, we assumed a reaction pathway as outlined in Scheme 4 . It is known that $\mathbf{5 b}$ undergoes a single hydroboration with Piers' borane to give 10, so we assume it to be the initial intermediate. ${ }^{11}$ With a second $\mathrm{HB}\left(\mathrm{C}_{6} \mathrm{~F}_{5}\right)_{2}$ equivalent this can then undergo the subsequent hydroboration reaction to give the geminal bis-boryl substituted compound $\mathbf{6 b}$. In the in situ NMR experiment we observed an intermediate which is likely $\mathbf{6 b}$ (for details, see the ESI†). This is not stable under our typical

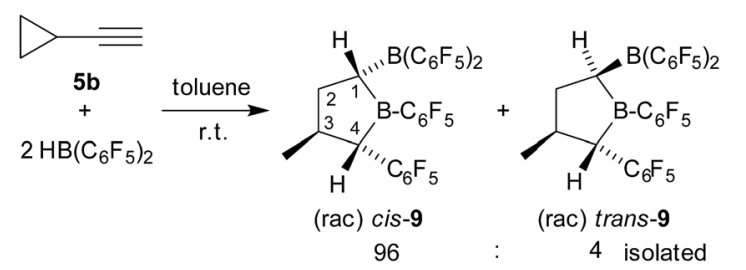

Scheme 3 Formation of the tetrahydroborole derivative 9 (with unsystematical atom numbering scheme as used in Fig. 3).

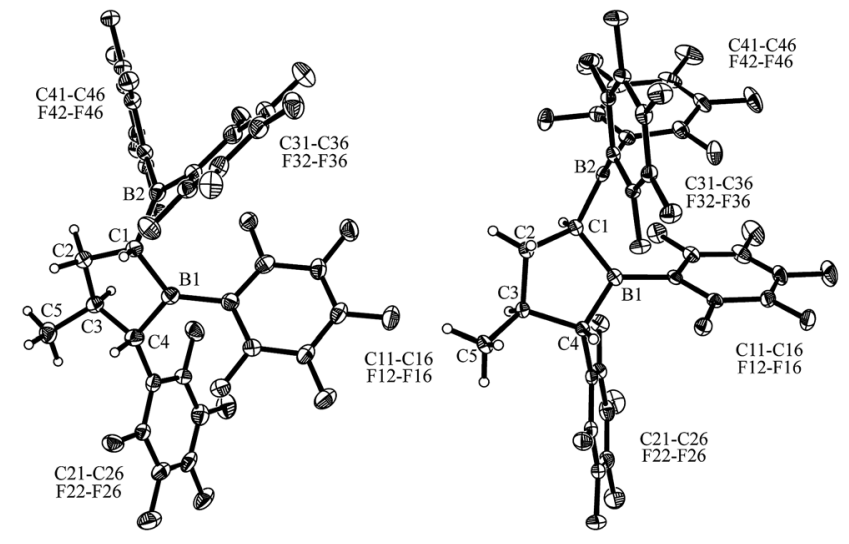

Fig. 3 A view of the molecular structures of the $\alpha$-boryl-tetrahydroborole cis-9 [left, thermal ellipsoids are shown with a 30\% probability level; selected bond lengths ( $\AA$ ) and angles (degrees): B1-C1 1.582(7), C1-B2 1.561(7), B1-C4 1.576(7), B2-C1-B1 120.3(4), C11-B1C4 125.5(4)] and the trans-9 epimer (right, thermal ellipsoids are shown with a $50 \%$ probability level; the separate synthesis of trans- 9 is described below). Selected bond lengths (Å) and angles (degrees): B1C1 1.588(2), C1-B2 1.543(2), B1-C4 1.579(2), B2-C1-B1 114.0(1), C11$\mathrm{B} 1-\mathrm{C} 4$ 124.3(1), $\sum \mathrm{B} 1^{\mathrm{cCC}} 360.0, \sum \mathrm{B} 2^{\mathrm{ccC}} 359.8$.

reaction conditions but undergoes Lewis acid induced cyclopropyl ring opening, potentially leading to $\mathbf{1 1}$ which is subsequently stabilized by a sequence of hydride $/ \mathrm{C}_{6} \mathrm{~F}_{5}$ 1,2-shifts to result in the observed product 9 . We must stress that we so far have no information about the alleged intermediates on the way and we cannot convincingly explain, let alone predict, the preferred stereochemical outcome, aside from the assumption that the formation of the observed cis-9 product is following a pathway of least steric hindrance on the way (Scheme 5).

The geminal bis-boryl compound contains a pair of Lewis acidic boron atoms and, consequently, it may serve as a chelate boron Lewis acid component in FLP chemistry. The isolated cis9 in conjunction with the phosphorus Lewis base $\mathrm{P}^{t} \mathrm{Bu}_{3}$ served as an active dihydrogen splitting reagent. Thus, treatment of a 1:1 mixture of cis-9 and $\mathrm{P}^{t} \mathrm{Bu}_{3}$ with dihydrogen $(2.0 \mathrm{bar})$ in pentane solution overnight produced the dihydrogen splitting product cis-12 as a precipitate. The salt cis-12 was isolated as a white solid with a $71 \%$ yield. We obtained single crystals of compound cis-12 from pentane/dichloromethane by a diffusion method which were suitable for characterization by X-ray

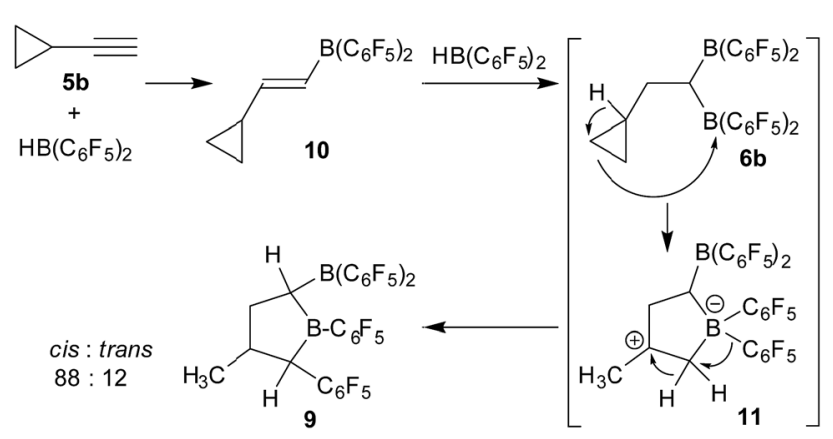

Scheme 4 Rearrangement reaction leading to 9. 


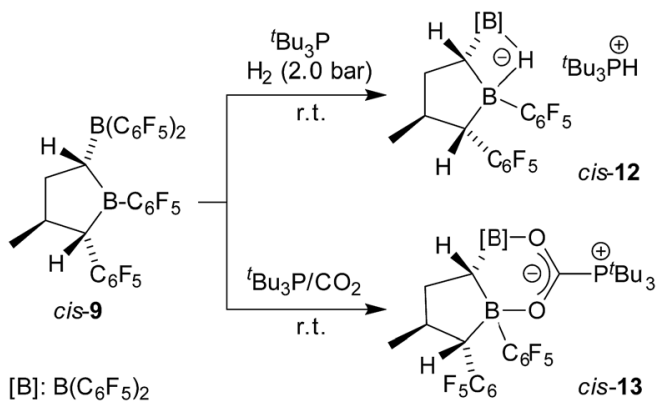

Scheme 5 FLP reactions of compound cis -9

diffraction (see Fig. 4). In the crystal, we see the typical r-1-boryl, t-3-methyl, c- $4-\mathrm{C}_{6} \mathrm{~F}_{5}$ arrangement ${ }^{\mathbf{1 2}}$ of the substituents on the tetrahydroborole framework. There is now a hydride bridging between the two boron atoms. ${ }^{13}$ Consequently, both the boron atoms B1 and B2 have attained distorted tetrahedral coordination geometries $\left(\sum \mathrm{B} 1^{\mathrm{ccc}}=345.3^{\circ}, \sum \mathrm{B} 2^{\mathrm{ccc}}=349.8^{\circ}\right)$, and we found the $\mathrm{HP}^{t} \mathrm{Bu}_{3}^{+}$cation in the crystal.

The bulk isolated product cis-12 (in $\mathrm{CD}_{2} \mathrm{Cl}_{2}$ ) contained $c a$. 15-20\% contamination of the isomer trans-12 since we had started from a not completely pure starting material (for details, see the ESI; $\uparrow$ the characterization of the independently synthesised isomer trans-12 will be described below). Compound cis-12 shows a pair of ${ }^{11} \mathrm{~B}$ NMR signals in the typical borate chemical shift range $(\delta=-14.5 \mathrm{ppm},-19.7 \mathrm{ppm})$. It shows a ${ }^{31} \mathrm{P}$ NMR phosphonium doublet at $\delta=60.6 \mathrm{ppm}$ with ${ }^{1} J_{\mathrm{PH}} \sim$ $428 \mathrm{~Hz}$. We also exposed the cis-9/P $\mathrm{P}^{t} \mathrm{Bu}_{3}$ FLP (again contaminated with a small amount of trans-9) to carbon dioxide (2.0 bar, r.t., overnight) in pentane solution. Under the typical conditions, the zwitterionic $\mathrm{FLP} / \mathrm{CO}_{2}$ addition product precipitated and was recovered by filtration to give cis-13 as a white solid

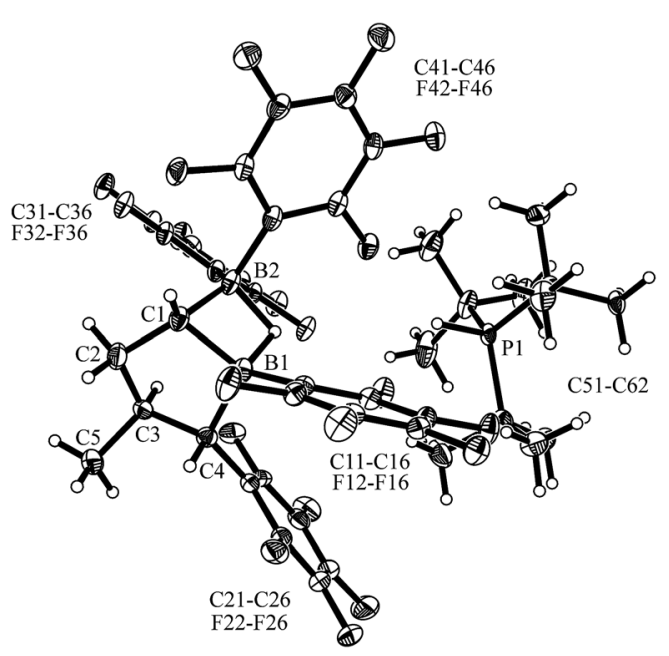

Fig. 4 Molecular structure of the dihydrogen splitting product cis-12 (thermal ellipsoids are shown with a 30\% probability level). Selected

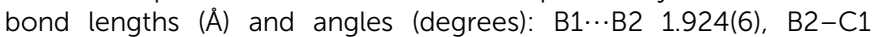
1.584(5), B2-H1, 1.33(3), C1-B1, 1.603(5), B1-C4 1.653(5), B1-H1 1.35(3), B2-C1-B1 74.3(2), B1-H1-B2 91.7. with a $73 \%$ yield. The NMR analysis (in THF- $\mathrm{d}_{8}$ ) again showed the presence of a second isomer (trans-13, see below, ca. 3\%).

Single crystals of cis-13 suitable for X-ray crystal structure analysis were obtained from pentane/dichloromethane at $-35{ }^{\circ} \mathrm{C}$ by the diffusion method (see Fig. 5). The compound contains a central heterocyclic six-membered ring that was formed by double chelate coordination of the geminal bis-boryl acceptor with the oxygen atoms of the phosphine activated carbon dioxide molecule. The structure of this subunit is largely delocalized with similar bond lengths in the B1-O1/B2-O2 pair as well as the $\mathrm{C} 6-\mathrm{O} 1 / \mathrm{O} 2$ pair of carbon-oxygen bonds. Carbon atom $\mathrm{C} 6$ has the $\mathrm{P}^{t} \mathrm{Bu}_{3}$ group attached to it. This chelate heterocycle is interlocked with the five-membered tetrahydroborole framework, which has the boron atom B1 incorporated in it. This section of the molecule shows the same characteristic stereochemical features as we had found for its precursor cis-9. The hydrogen atoms at $\mathrm{C} 1 / \mathrm{C} 4$ and the methyl substituent at carbon atom $\mathrm{C} 3$ are all in a cis-arrangement on this five-membered ring.

The boryl tetrahydroborole system 9 contains three independent carbon chirality centres. Therefore, there is the possibility of forming four diastereoisomers. So far our rearrangement reaction was rather stereoselective and produced the major product cis-9 with the relative stereoselectivity $\mathrm{r}-1, \mathrm{t}-3, \mathrm{c}-4$ plus a small amount of a minor isomer which probably represents one of the other three diastereoisomers, but whose relative stereochemistry we did not know. We have now prepared and characterized the isomer "trans-9" (of relative $\mathrm{r}-1, \mathrm{c}-3, \mathrm{t}-4$ stereochemistry) by a selective isomerization process at the saturated central heterocyclic framework.

For that purpose, we treated the substituted tetrahydroborole product cis-9 $[\mathrm{r}-1, \mathrm{t}-3, \mathrm{c}-4]$ with a catalytic amount $(20 \mathrm{~mol} \%)$ of the persistent nitroxide radical TEMPO (pentane, r.t., 4 days). ${ }^{\mathbf{1 1 1 4}}$ This reaction apparently proceeded with reversible $\mathrm{H}$-atom abstraction at the activated $\mathrm{C} 1$ position of the heterocycle and we isolated the trans-9 epimer [r-1, c-3, t-4] as a colourless solid with a $74 \%$ yield. This compound was characterized by $\mathrm{C}, \mathrm{H}$-elemental analysis, by NMR spectroscopy $\left({ }^{11} \mathrm{~B}: \delta=79.6 \mathrm{ppm}, 72.9 \mathrm{ppm}\right.$, for details see the ESI $\left.\dagger\right)$ and by Xray diffraction. Single crystals suitable for the X-ray crystal structure analysis of compound trans-9 were obtained from a pentane/dichloromethane mixture at $-35^{\circ} \mathrm{C}$ (see Fig. 3, right). It shows the typical five-membered tetrahydroborole framework with the $\mathrm{B}\left(\mathrm{C}_{6} \mathrm{~F}_{5}\right)_{2}$ and $\mathrm{C}_{6} \mathrm{~F}_{5}$ substituents at carbon atoms $\mathrm{C} 1$ and $\mathrm{C} 4$ now in a trans relationship. The methyl group at $\mathrm{C} 3$ has remained trans oriented to the $\mathrm{C}_{6} \mathrm{~F}_{5}$ group at $\mathrm{C} 4$.

Compound trans-9 also formed an active frustrated Lewis pair with $\mathrm{P}^{t} \mathrm{Bu}_{3}$. The system heterolytically cleaved dihydrogen at near to ambient conditions (pentane, r.t., 2.0 bar $\mathrm{H}_{2}$, overnight), and we isolated the hydridoborate/phosphonium salt with a $62 \%$ yield. It shows typical ${ }^{11} \mathrm{~B}$ NMR signals at $\delta=-13.3 \mathrm{ppm}$ and $-17.1 \mathrm{ppm}$ and ${ }^{31} \mathrm{P}$ NMR feature at $\delta=60.7 \mathrm{ppm}\left({ }^{1} J_{\mathrm{PH}} \sim 428 \mathrm{~Hz}\right)$. Compound trans-12 was characterized by X-ray diffraction (single crystals were obtained from pentane/dichloromethane at r.t. by the diffusion method). The $\mathrm{X}$-ray crystal structure analysis (see Fig. 6) showed the presence of the hydride bridged pair of boron atoms inside the anion and 

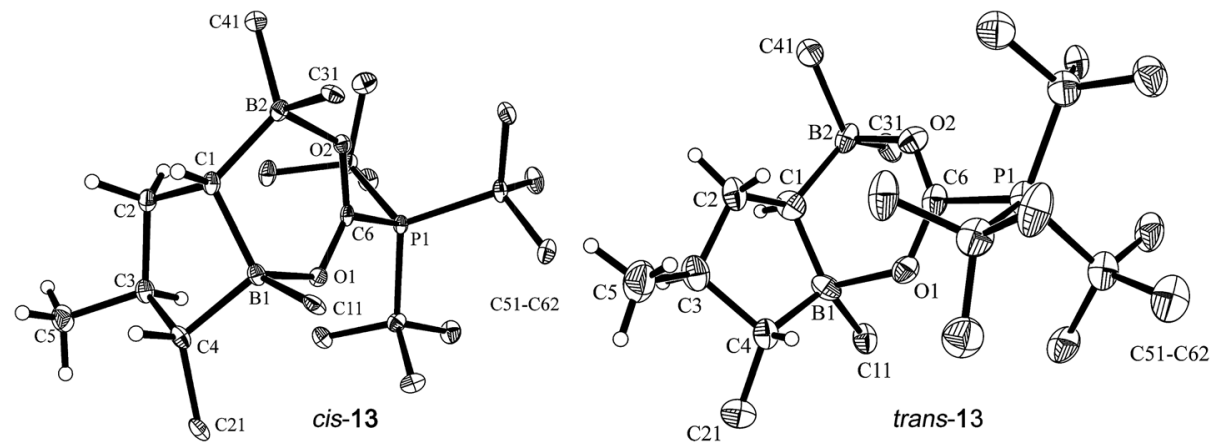

Fig. 5 Projection of the molecular structures of the $\mathrm{FLP} / \mathrm{CO}_{2}$ addition product cis-13 [left, thermal ellipsoids are shown with a $50 \%$ probability level; hydrogen atoms of the $\mathrm{P}^{t} \mathrm{Bu}_{3}$ group and the $\mathrm{C}_{6} \mathrm{~F}_{5}$ substituents at boron atoms $\mathrm{B} 1, \mathrm{~B} 2$, and at carbon atom $\mathrm{C} 4$ are omitted for clarity: for details see the ESI; $\uparrow$ selected bond lengths (Å) and angles (degrees): P1-C6 1.905(2), B1-O1 1.657(2), B2-O2 1.636(2), O2-C6 1.258(2), O1-C6 1.255(2), O1-C6-O2 128.0(2), B2-C1-B1 110.9(2)] and trans-13 [right, the independent synthesis of trans-13 is described below; thermal ellipsoids are shown with a $30 \%$ probability level; hydrogen atoms of the $\mathrm{P}^{t} \mathrm{Bu}_{3}$ group and the $\mathrm{C}_{6} \mathrm{~F}_{5}$ substituents at boron atoms $\mathrm{B} 1$, $\mathrm{B} 2$, and at carbon atom C4 are omitted for clarity: for details see the ESI; $\uparrow$ selected bond lengths ( $\AA$ ) and angles (degrees): P1-C6 1.913(10), B1-O1 1.717(13), B2-O2 1.634(13), O2-C6 1.248(12), O1-C6 1.271(12), O1-C6-O2 128.7(9), B2-C1-B1 118.1(9)].

the separate $\mathrm{HP}^{t} \mathrm{Bu}_{3}{ }^{+}$cation. The framework of compound trans12 features the expected trans-orientation of the $\mathrm{B}(\mathrm{H})\left(\mathrm{C}_{6} \mathrm{~F}_{5}\right)_{2} /$ $\mathrm{C}_{6} \mathrm{~F}_{5}$ pair of substituents at the ring carbon atoms $\mathrm{C} 1 / \mathrm{C} 4$ and the vicinal trans-orientation of the $\mathrm{C}^{-}-\mathrm{CH}_{3}$ group with the $\mathrm{C} 4-$ $\mathrm{C}_{6} \mathrm{~F}_{5}$ substituent. The system has consequently conserved the relative stereochemistry of the starting material trans-9. Compound trans-12 shows a relative stereochemistry of $\mathrm{r}-1, \mathrm{c}-3$, t-4 (see Scheme 6 and Fig. 6).

Compound trans-9 also reacts with carbon dioxide in the presence of $\mathrm{P}^{t} \mathrm{Bu}_{3}$. Exposing a mixture of trans-9 and tris $($ tertbutyl)phosphine in pentane solution overnight at r.t. to a $\mathrm{CO}_{2}$ atmosphere gave the $\mathrm{FLP} / \mathrm{CO}_{2}$ adduct trans-13 as a white precipitate with a $76 \%$ yield. The compound turned out to be only sparingly soluble in many solvents. However it could be characterized by X-ray diffraction using single crystals that were directly obtained from the reaction mixture of trans $-9 / \mathrm{P}^{t} \mathrm{Bu}_{3}$ with $\mathrm{CO}_{2}$. The structure (see Fig. 5, right) confirmed the

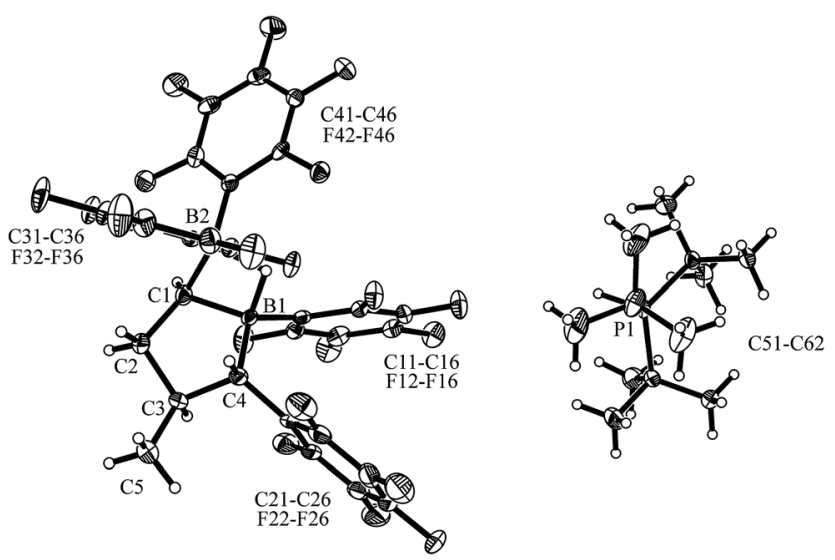

Fig. 6 A view of the molecular structure of the hydridoborate/phosphonium salt trans-12 (thermal ellipsoids are shown with a 50\% probability level). Selected bond lengths ( $\AA$ ) and angles (degrees): B1… B2 1.909(5), B2-C1 1.584(5), B1-C1 1.596(4), B1-C4 1.636(5), B2-H1 1.31(3), B1-H1 1.30(4), B2-C1-B1 73.8(2), B1-H1-B2 93.8. stereochemical assignment of the backbone of the compounds of this trans-series: in compound trans-13 the boryl substituent at carbon atom $\mathrm{C} 1$ is in a trans relationship with the $\mathrm{C}_{6} \mathrm{~F}_{5}$ substituent at the distal ring carbon atom $\mathrm{C}$, and the latter is oriented trans relative to the methyl group at C3. Consequently, the relative positions of the three substituents at the central tetrahydroborole framework in compound trans-13 are $\mathrm{r}-1$ boryl, c-3-methyl, t-4- $\mathrm{C}_{6} \mathrm{~F}_{5}$ configured. The $\mathrm{CO}_{2}$ oxygen atoms are found to be bonded to the pair of boron Lewis acid sites and the phosphorus atom is coordinated to the $\mathrm{CO}_{2}$ carbon atom. The $\mathrm{CO}_{2}$ bonding to the geminal bis(borane) acceptor is slightly unsymmetrical with the $\mathrm{B} 1-\mathrm{O} 1$ bond in the central position being markedly longer than the lateral $\mathrm{B} 2-\mathrm{O} 2$ contact and also the P1-C6 linkage is rather long (see Fig. 5). Compound trans-13 was just sufficiently soluble in $\mathrm{d}_{8}$-THF to allow the recording of most of its NMR features. The actual sample used was $c a .90 \%$ pure, and it contained a minor compound of unknown composition. Compound trans-13 shows a ${ }^{31} \mathrm{P}$ NMR resonance at $\delta=57.4 \mathrm{ppm}$. The ${ }^{13} \mathrm{C}$ NMR signal of the $\mathrm{CO}_{2}$ derived moiety

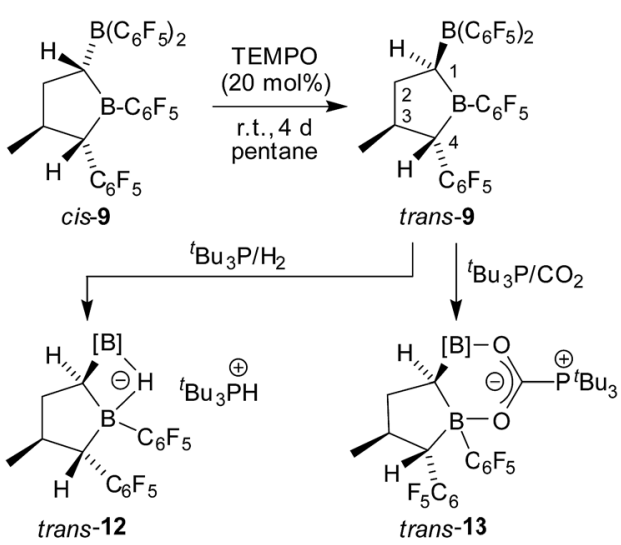

$[B]: B\left(C_{6} F_{5}\right)_{2}$

Scheme 6 Isomerization of compound cis-9 and the FLP reactions of trans-9. 
occurs at $\delta=173.4 \mathrm{ppm}\left({ }^{1} J_{\mathrm{PC}}=90.0 \mathrm{~Hz}\right)$ and compound trans -13 features a total of six $o$ - (two overlapping), four $p$ - and four $m$ $\mathrm{C}_{6} \mathrm{~F}_{5}{ }^{19} \mathrm{~F}$ NMR signals in $\mathrm{d}_{8}$-THF at $233 \mathrm{~K}$ (for further details see the ESI $\dagger$ ).

\section{Conclusions}

We have shown in this study that the reaction of cyclopropylacetylene with two molar equivalents of Piers' borane $\left[\mathrm{HB}\left(\mathrm{C}_{6} \mathrm{~F}_{5}\right)_{2}\right]$ takes an unusual course. We assume that initially the usual two-fold hydroboration reaction of the terminal alkyne takes place with the anti-Markovnikov orientation generating the respective geminal bis-boryl compound. This is apparently not stable under the applied mild reaction conditions, but undergoes an intramolecular rearrangement process initiated by cyclopropyl ring opening by the adjacent strong borane Lewis acid. This initiates a series of 1,2-migration reactions involving the migration of one $\mathrm{C}_{6} \mathrm{~F}_{5}$ group from boron to carbon which eventually yields the $\alpha$-boryl tetrahydroborole system 9. This is obtained with a rather high diastereoselectivity from this rearrangement process. The major compound cis-9 is an active FLP dihydrogen cleavage reagent in the presence of the bulky $\mathrm{P}^{t} \mathrm{Bu}_{3}$ Lewis base. The cis-9/P ${ }^{t} \mathrm{Bu}_{3} \mathrm{FLP}$ also sequesters $\mathrm{CO}_{2}$ cleanly in a chelate fashion, similar to the here studied more Lewis acidic geminal $\mathrm{R}-\mathrm{CH}\left[\mathrm{B}\left(\mathrm{C}_{6} \mathrm{~F}_{5}\right)_{2}\right]_{2}$ reference systems, despite the loss of one electron withdrawing $\mathrm{C}_{6} \mathrm{~F}_{5}$ substituent at a boron atom. This probably indicates the favourable influence of the geminal bis-boryl situation for both chelate hydride and chelate $\mathrm{CO}_{2}$ binding.

\section{Experimental section}

\section{Preparation of compound 6a}

A solution of 4-phenyl-1-butyne (5a, $65.0 \mathrm{mg}, 0.50 \mathrm{mmol})$ in toluene $(1.0 \mathrm{~mL})$ was added to a suspension of bis(pentafluorophenyl)borane (345 mg, $1.00 \mathrm{mmol}$ ) and toluene $(3.0 \mathrm{~mL})$. The reaction mixture was stirred at room temperature for 1 hour and then the suspension was filtered by cannula filtration. The volatiles of the obtained filtrate were removed in vacuo to give a colorless oil. Subsequently pentane $(4.0 \mathrm{~mL})$ was added and the mixture was stored at $c a .-35{ }^{\circ} \mathrm{C}$ overnight. The formed white powder was isolated by filtration, washed with pentane $(2 \times 1 \mathrm{~mL})$ and dried in vacuo to give compound $6 \mathbf{6}(312 \mathrm{mg}$, $0.38 \mathrm{mmol}, 76 \%$ ) as a white solid. Anal. calc. for $\mathrm{C}_{34} \mathrm{H}_{12} \mathrm{~B}_{2} \mathrm{~F}_{20}$ : C, $49.68 \%$; H, $1.47 \%$. Found: C, $49.40 \%$; H, 1.40\%. For the NMR data see the ESI. $\dagger$

\section{Preparation of compound 7}

A solution of compound $6 \mathrm{a}(82.2 \mathrm{mg}, 0.10 \mathrm{mmol})$ and tri-tertbutylphosphine $(20.5 \mathrm{mg}, 0.10 \mathrm{mmol})$ in pentane $(3.0 \mathrm{~mL})$ was exposed to a hydrogen atmosphere $(2.0$ bar) at room temperature and stirred overnight. The resulting white precipitate was collected by cannula filtration and washed with pentane $(3 \times$ $2 \mathrm{~mL}$ ). After the removal of all volatiles in vacuo, compound 7 was obtained (88.6 mg, $0.087 \mathrm{mmol}, 87 \%$ ) as a white solid. Anal. calc. for $\mathrm{C}_{46} \mathrm{H}_{41} \mathrm{~B}_{2} \mathrm{~F}_{20} \mathrm{P}: \mathrm{C}, 53.83 \% ; \mathrm{H}, 4.03 \%$. Found: C, $53.81 \%$;
$\mathrm{H}, 4.01 \%$. Single crystals suitable for the X-ray crystal structure analysis were obtained by the slow diffusion of pentane into a solution of compound 7 in dichloromethane at $-35^{\circ} \mathrm{C}$.

\section{Preparation of compound 8}

A solution of compound $\mathbf{6 a}(123.3 \mathrm{mg}, 0.15 \mathrm{mmol})$ and tri-tertbutylphosphine $(30.3 \mathrm{mg}, 0.15 \mathrm{mmol})$ in pentane $(5.0 \mathrm{~mL})$ was exposed to $\mathrm{CO}_{2}$ (2.0 bar) at room temperature and then stirred for 2 hours. The resulting white precipitate was isolated by cannula filtration and washed with pentane $(3 \times 1 \mathrm{~mL})$. After drying the solid in vacuo, compound 8 (129.4 $\mathrm{mg}, 0.12 \mathrm{mmol}$, $81 \%$ ) was obtained as a white powder. Anal. calc. for $\mathrm{C}_{47} \mathrm{H}_{39} \mathrm{~B}_{2} \mathrm{~F}_{20} \mathrm{O}_{2} \mathrm{P}: \mathrm{C}, 52.84 \% ; \mathrm{H}, 3.68 \%$. Found: C, 53.21\%; $\mathrm{H}$, $3.91 \%$. Single crystals of compound 8 suitable for the X-ray crystal structure analysis were obtained by the slow diffusion of pentane into a solution of the white powder in dichloromethane at $-35{ }^{\circ} \mathrm{C}$.

\section{Preparation of compound cis-9}

A solution of compound $5 \mathbf{b}(33.0 \mathrm{mg}, 0.50 \mathrm{mmol})$ in toluene (1.0 mL) was added to a suspension of bis(pentafluorophenyl)borane (345 $\mathrm{mg}, 1.00 \mathrm{mmol})$ and toluene $(3.0 \mathrm{~mL})$. After stirring the reaction mixture at room temperature for 1 hour, the solution was separated from the resulting suspension by cannula filtration. Then all volatiles of the filtrate were removed in vacuo to give a yellow oil, which was dissolved in pentane $(2.5 \mathrm{~mL})$ and stored at $-35{ }^{\circ} \mathrm{C}$ overnight. The precipitated pale yellow solid was isolated by filtration and washed with cold pentane $(2 \times$ $0.5 \mathrm{~mL}$ ). The removal of all volatiles in vacuo gave a pale yellow solid (253 mg, $0.34 \mathrm{mmol}, 67 \%$ ). Anal. calc. for $\mathrm{C}_{29} \mathrm{H}_{8} \mathrm{~B}_{2} \mathrm{~F}_{20}: \mathrm{C}$, $45.95 \%$; H, 1.06\%. Found: C, 45.74\%; H, 1.07\%. Crystals of compound cis-9 suitable for the X-ray crystal structure analysis were obtained from a solution of the yellow solid in pentane at $-35{ }^{\circ} \mathrm{C}$.

\section{Preparation of compound trans-9}

TEMPO (16.6 mg, $0.11 \mathrm{mmol}$ ) was added to a solution of compound cis-9 (400 mg, $0.53 \mathrm{mmol})$ in pentane $(15 \mathrm{~mL})$. After stirring the reaction mixture at r.t. for 4 days, the resulting suspension was concentrated to about $2.0 \mathrm{~mL}$, and stored in the fridge $\left(-35{ }^{\circ} \mathrm{C}\right)$ overnight. The precipitated white powder was isolated via cannula filtration, and washed with cold pentane $(2 \times 1.0 \mathrm{~mL})$. The removal of all volatiles under reduced pressure gave product trans $\mathbf{- 9}$ (296 mg, $0.39 \mathrm{mmol}, 74 \%$ ) as a white solid. Anal. calc. for $\mathrm{C}_{29} \mathrm{H}_{8} \mathrm{~B}_{2} \mathrm{~F}_{20}$ : C, 45.95\%; H, 1.06\%. Found: $\mathrm{C}$, $45.45 \% ; \mathrm{H}, 0.95 \%$. Crystals suitable for the X-ray crystal structure analysis were obtained from a solution of compound trans9 in pentane $(1.5 \mathrm{~mL})$ and $\mathrm{CH}_{2} \mathrm{Cl}_{2}(0.5 \mathrm{~mL})$ at $-35{ }^{\circ} \mathrm{C}$.

\section{Preparation of compound cis-12}

A solution of compound cis-9 (cis/trans $\approx 96 / 4$, vide supra) $(113.7 \mathrm{mg}, 0.15 \mathrm{mmol})$ and tri-tert-butylphosphine $(30.3 \mathrm{mg}$, $0.15 \mathrm{mmol})$ in pentane $(5.0 \mathrm{~mL})$ was exposed to dihydrogen (2.0 bar) at room temperature and then stirred overnight. The formed white precipitate was collected by cannula filtration and 
washed with pentane $(3 \times 1 \mathrm{~mL})$. After the removal of all volatiles in vacuo, a white solid was obtained $(101.4 \mathrm{mg}, 0.11 \mathrm{mmol}$, $71 \%$ ). Anal. calc. for $\mathrm{C}_{41} \mathrm{H}_{37} \mathrm{~B}_{2} \mathrm{~F}_{20} \mathrm{P}: \mathrm{C}, 51.17 \% ; \mathrm{H}, 3.88 \%$. Found: C, $50.96 \%$; H, 3.76\%. Single crystals of compound cis-12 suitable for the X-ray crystal structure analysis were obtained by the slow diffusion of $n$-pentane into a solution of the white solid in dichloromethane at room temperature.

\section{Preparation of compound trans-12}

A solution of compound trans $-9(75.8 \mathrm{mg}, 0.10 \mathrm{mmol})$ and tritert-butylphosphine $(20.2 \mathrm{mg}, 0.10 \mathrm{mmol})$ in pentane $(4.0 \mathrm{~mL})$ was exposed to a dihydrogen atmosphere $(2.0 \mathrm{bar})$ at room temperature and stirred overnight. The formed white precipitate was collected by cannula filtration and washed with $n$ pentane $(2 \times 1 \mathrm{~mL})$. The removal of all volatiles in vacuo gave compound trans-12 (59.2 mg, $0.062 \mathrm{mmol}, 62 \%)$ as a white solid. Anal. calc. for $\mathrm{C}_{41} \mathrm{H}_{37} \mathrm{~B}_{2} \mathrm{~F}_{20} \mathrm{P}: \mathrm{C}, 51.17 \% ; \mathrm{H}, 3.88 \%$. Found: C, $51.09 \%$; H, 3.67\%. Single crystals suitable for X-ray crystal structure analysis were obtained by the slow diffusion of pentane into a solution of compound trans-12 in dichloromethane at room temperature.

\section{Preparation of compound cis-13}

A solution of compound cis-9 (cis/trans $\approx 96 / 4$, vide supra) $(113.7 \mathrm{mg}, 0.15 \mathrm{mmol})$ and tri-tert-butylphosphine $(30.3 \mathrm{mg}$, $0.15 \mathrm{mmol})$ in pentane $(5.0 \mathrm{~mL})$ was exposed to a $\mathrm{CO}_{2}$ atmosphere (2.0 bar) and then stirred overnight at room temperature. The formed white precipitate was collected by cannula filtration and washed with pentane $(3 \times 1 \mathrm{~mL})$. After the removal of all volatiles in vacuo, a white solid was obtained (108.3 mg, $0.11 \mathrm{mmol}, 73 \%$ ). Anal. calc. for $\mathrm{C}_{42} \mathrm{H}_{35} \mathrm{~B}_{2} \mathrm{~F}_{20} \mathrm{O}_{2} \mathrm{P}: \mathrm{C}$, $50.23 \%$; H, 3.51\%. Found: C, 50.07\%; H, 3.36\%. Single crystals of compound cis-13 suitable for the X-ray crystal structure analysis were obtained by the slow diffusion of $n$-pentane into a solution of the obtained white solid in dichloromethane at $-35{ }^{\circ} \mathrm{C}$.

\section{Preparation of compound trans-13}

A solution of compound trans $-9(75.8 \mathrm{mg}, 0.10 \mathrm{mmol})$ and tritert-butylphosphine $(20.2 \mathrm{mg}, 0.10 \mathrm{mmol})$ in pentane $(5.0 \mathrm{~mL})$ was exposed to $\mathrm{CO}_{2}(2.0 \mathrm{bar})$ at room temperature and then stirred overnight. The formed white precipitate was collected by cannula filtration and washed with pentane $(3 \times 1 \mathrm{~mL})$. After the removal of all volatiles in vacuo, compound trans-13 (76.2 mg, $0.076 \mathrm{mmol}, 76 \%$ ) was obtained as a white solid. Anal. calc. for $\mathrm{C}_{42} \mathrm{H}_{35} \mathrm{~B}_{2} \mathrm{~F}_{20} \mathrm{O}_{2} \mathrm{P}: \mathrm{C}, 50.23 \% ; \mathrm{H}, 3.51 \%$. Found: $\mathrm{C}$, $49.96 \% ; \mathrm{H}, 3.27 \%$. Single crystals of compound trans-13 suitable for the X-ray crystal structure analysis were obtained directly from a reaction solution of compound trans-9 $(37.9 \mathrm{mg})$ and tritert-butylphosphine $(10.1 \mathrm{mg})$ and dichloromethane $(1.0 \mathrm{~mL})$ in a $\mathrm{CO}_{2}$ atmosphere (2.0 bar) at room temperature.

\section{Acknowledgements}

Financial support from the Alexander von Humboldt-Stiftung (stipend to Y. L. L.) is gratefully acknowledged.

\section{Notes and references}

1 D. J. Parks, R. E. von H. Spence and W. E. Piers, Angew. Chem., Int. Ed. Engl., 1995, 34, 809.

2 (a) D. J. Parks, W. E. Piers and G. P. A. Yap, Organometallics, 1998, 17, 5492. See also: (b) J.-H. Lamm, J. Horstmann, J. H. Nissen, J.-H. Weddeling, B. Neumann, H.-G. Stammler and N. W. Mitzel, Eur. J. Inorg. Chem., 2014, 4294.

3 W. Siebert, M. Hildenbrand, P. Hornbach, G. Karger and H. Pritzkow, Z. Naturforsch., B: J. Chem. Sci., 1989, 44, 1179. 4 X. Zhao and D. W. Stephan, Chem. Commun., 2011, 47, 1833. 5 Selected examples of $\mathrm{CO}_{2}$ binding using non-chelate borane Lewis acids: (a) C. M. Mömming, E. Otten, G. Kehr, R. Fröhlich, S. Grimme, D. W. Stephan and G. Erker, Angew. Chem., Int. Ed., 2009, 48, 6643; (b) G. Ménard and D. W. Stephan, J. Am. Chem. Soc., 2010, 132, 1796; (c) I. Peuser, R. C. Neu, X. Zhao, M. Ulrich, B. Schirmer, J. A. Tannert, G. Kehr, R. Fröhlich, S. Grimme, G. Erker and D. W. Stephan, Chem.-Eur. J., 2011, 17, 9640; (d) C. Appelt, H. Westenberg, F. Bertini, A. W. Ehlers, J. C. Slootweg, K. Lammertsma and W. Uhl, Angew. Chem., Int. Ed., 2011, 50, 3925; (e) J. Boudreau, M. A. Courtemanche and F. G. Fontaine, Chem. Commun., 2011, 47, 11131; $(f)$ A. M. Chapman, M. F. Haddow and D. F. Wass, J. Am. Chem. Soc., 2011, 133, 8826; $(g)$ A. M. Chapman, M. F. Haddow and D. F. Wass, J. Am. Chem. Soc., 2011, 133, 18463; (h) M. Harhausen, R. Fröhlich, G. Kehr and G. Erker, Organometallics, 2012, 31, 2801; (i) F. Bertini, V. Lyaskovskyy, B. J. J. Timmer, F. J. J. de Kanter, M. Lutz, A. W. Ehlers, J. C. Slootweg and K. Lammertsma, J. Am. Chem. Soc., 2012, 134, 201; (j) X. Xu, G. Kehr, C. G. Daniliuc and G. Erker, J. Am. Chem. Soc., 2013, 135, 6465; (k) S. Frömel, G. Kehr, R. Fröhlich, C. G. Daniliuc and G. Erker, Dalton Trans., 2013, 42, 14531; (l) M. J. Sgro and D. W. Stephan, Chem. Commun., 2013, 49, 2610; $(m)$ D. Voicu, M. Abolhasani, R. Choueiri, G. Lestari, C. Seiler, G. Ménard, J. Greener, A. Guenther, D. W. Stephan and E. Kumacheva, J. Am. Chem. Soc., 2014, 136, 3875.

6 Selected examples of FLP mediated $\mathrm{CO}_{2}$ reduction using non-chelate Lewis acids: (a) A. E. Ashley, A. L. Thompson and D. O'Hare, Angew. Chem., Int. Ed., 2009, 48, 9839; (b) A. Berkefeld, W. E. Piers and M. Parvez, J. Am. Chem. Soc., 2010, 132, 10660; (c) G. Ménard and D. W. Stephan, Angew. Chem., Int. Ed., 2011, 50, 8396; (d) K. Takeuchi and D. W. Stephan, Chem. Commun., 2012, 48, 11304; (e) M. J. Sgro and D. W. Stephan, Angew. Chem., Int. Ed., 2012, 51, 11343; $(f)$ R. Dobrovetsky and D. W. Stephan, Angew. Chem., Int. Ed., 2013, 52, 2516; $(g)$ M. A. Courtemanche, M. A. Legare, L. Maron and F. G. Fontaine, J. Am. Chem. Soc., 2013, 135, 9326; (h) T. Wang and D. W. Stephan, Chem.-Eur. J., 2014, 20, 3036; (i) T. Wang and D. W. Stephan, Chem. Commun., 2014, 50, 7007; (j) R. Declercq, G. Bouhadir, D. Bourissou, M.-A. Légaré, M.-A. Courtemanche, K. S. Nahi, N. Bouchard, F.-G. Fontaine and L. Maron, ACS Catal., 2015, 5, 2513; (k) 
M. A. Courtemanche, A. P. Pulis, É. Rochette, M. A. Légaré, D. W. Stephan and F. G. Fontaine, Chem. Commun., 2015, 51, 9797.

7 For reviews, see: (a) H. C. Brown and P. V. Ramachandran, Pure Appl. Chem., 1991, 63, 307; (b) H. C. Brown and P. V. Ramachandran, J. Organomet. Chem., 1995, 500, 1; (c) I. Beletskaya and A. Pelter, Tetrahedron, 1997, 53, 4957; (d) R. Barbeyron, E. Benedetti, J. Cossy, J.-J. Vasseur, S. Arseniyadis and M. Smietana, Tetrahedron, 2014, 70, 8431.

8 D. L. Bryce, R. E. Wasylishen and M. Gee, J. Phys. Chem. A, 2001, 105, 3633.

9 For reviews, see: (a) D. W. Stephan and G. Erker, Angew. Chem., Int. Ed., 2010, 49, 46; (b) D. W. Stephan and G. Erker, Angew. Chem., Int. Ed., 2015, 54, 6400. For leading examples, see: (c) G. C. Welch, R. R. S. Juan, J. D. Masuda and D. W. Stephan, Science, 2006, 314, 1124; (d) G. C. Welch and D. W. Stephan, J. Am. Chem. Soc., 2007, 129, 1880; (e) P. Spies, G. Erker, G. Kehr, K. Bergander, R. Fröhlich, S. Grimme and D. W. Stephan, Chem. Commun., 2007, 5072.

10 (a) A. Feldmann, A. Iida, R. Fröhlich, S. Yamaguchi, G. Kehr and G. Erker, Organometallics, 2012, 31, 2445; (b)
M. M. Hansmann, R. L. Melen, M. Rudolph, F. Rominger, H. Wadepohl, D. W. Stephan and A. S. K. Hashmi, J. Am. Chem. Soc., 2015, 137, 15469; (c) S. Tamke, Z.-W. Qu, N. A. Sitte, U. Flörke, S. Grimme and J. Paradies, Angew. Chem., Int. Ed., 2016, 55, 4336; (d) See for a comparison: R. A. Adler Yanez, G. Kehr, C. G. Daniliuc, B. Schirmer and G. Erker, Dalton Trans., 2014, 43, 10794.

11 F. Türkyilmaz, G. Kehr, J. Li, C. G. Daniliuc, M. Tesch, A. Studer and G. Erker, Angew. Chem., Int. Ed., 2016, 55, 1470. 12 The stereochemical nomenclature is used according to IUPAC, see J. Org. Chem., 1970, 35, 2849.

13 (a) P. Moquist, G.-Q. Chen, C. Mück-Lichtenfeld, K. Bussmann, C. G. Daniliuc, G. Kehr and G. Erker, Chem. Sci., 2015, 6, 816; (b) S. Kohrt, S. Dachwitz, C. G. Daniliuc, G. Kehr and G. Erker, Dalton Trans., 2015, 44, 21032; (c) J. Yu, G. Kehr, C. G. Daniliuc and G. Erker, Chem. Commun., 2016, 52, 1393.

14 For reviews, see: (a) L. Tebben and A. Studer, Angew. Chem., Int. Ed., 2011, 50, 5034; (b) A. Studer and D. P. Curran, Nat. Chem., 2014, 6, 765; (c) A. Studer and D. P. Curran, Angew. Chem., Int. Ed., 2016, 55, 58. 